\title{
Osmotically induced oligo- and polysaccharide synthesis by Rhizobium meliloti SU-47
}

\author{
M. W. Breedveld, ${ }^{*}$ L. P. T. M. Zevenhuizen and A. J. B. Zehnder \\ Department of Microbiology, Agricultural University, Hesselink van Suchtelenweg 4, 6703 CT Wageningen, \\ The Netherlands
}

(Received 11 June 1990; accepted 9 August 1990)

\begin{abstract}
In standard liquid medium containing $5 \mathrm{~g}$ mannitol $\mathrm{l}^{-1}$ and $1 \mathrm{~g}$ glutamic acid $\mathrm{l}^{-1}$, Rhizobium meliloti SU-47 cells accumulated $350 \mathrm{mg}$ cyclic 1,2- $\beta$-glucans (g protein) ${ }^{-1}$. The cyclic glucans were $36 \%$ glycerol-1-phosphate-

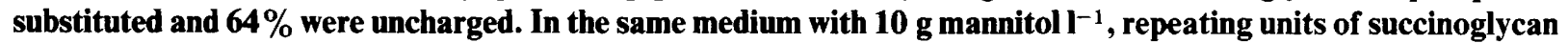
(1110 $\mathrm{mg} \mathrm{l}^{-1}$ ) were found as extracellular carbohydrates, and only low amounts of the succinoglycan polymer (up to $300 \mathrm{mg} \mathrm{l}^{-1}$ ) were excreted. By raising the osmotic pressure of the medium by the addition of $\mathrm{NaCl}$ or other ionic and non-ionic osmolytes, succinoglycan production could be stimulated: up to $2.4 \mathrm{~g} \mathrm{l}^{-1}$ at $0.2 \mathrm{M}-\mathrm{NaCl}$ was produced at the expense of the repeating units. Above $0.2 \mathrm{M}-\mathrm{NaCl}$ growth was slowed down, and succinoglycan excretion diminished. At $1 \mathrm{M}-\mathrm{NaCl}$ growth stopped completely. In standard medium containing $0.6 \mathrm{M}-\mathrm{NaCl}$ the amount of cellular cyclic 1,2- $\beta$-glucans was lowered to $150 \mathrm{mg}$ (g protein) ${ }^{-1}$ out of which the glycerol-1-phosphatesubstituted glucan fraction was reduced to $15 \%$. Instead, high amounts of oligosaccharides were synthesized as osmoprotectants, with trehalose as the major component [up to $200 \mathrm{mg}$ (g protein) ${ }^{-1}$ ]. Glycogen synthesis was completely suppressed at this salt concentration, while poly $\beta$-hydroxybutyric acid synthesis was unaffected.
\end{abstract}

\section{Introduction}

Cyclic 1,2- $\beta$-glucans of rhizobia are considered to function as osmoregulants in order to equilibrate the osmotic balance between the cytoplasm and the periplasm, in particular at low osmotic values of the medium (Miller et al., 1986). They are localized in the periplasmic space (Abe et al., 1982). Cyclic 1,2- $\beta$-glucans were isolated for the first time from the extracellular fluid of an Agrobacterium tumefaciens culture (McIntire et al., 1942). Since then, several authors have found $1,2-\beta$ glucans in the cell (Zevenhuizen and Scholten-Koerselman, 1979; Miller et al., 1986) or in the medium (Amemura et al., 1983, 1985; Zevenhuizen, 1986) of a number of Rhizobium and Agrobacterium species.

Cellular concentrations of 1,2- $\beta$-glucans follow a distinct pattern depending on the species and the growth phase. In mannitol-glutamic acid-salts medium of low osmotic value cells of $R$. leguminosarum, biovars viciae, trifolii and phaseoli build up concentrations of $1,2-\beta$ -

\footnotetext{
Abbreviations: CPS, capsular polysaccharide, DP, degree of polymerization; EPS extracellular polysaccharide; PHB, poly $\beta$-hydroxybutyric acid.
}

glucans to a maximum of $100 \mathrm{mg}$ (g dry cell wt) ${ }^{-1}$ at the end of the exponential phase. Their concentrations are reduced by more than $50 \%$ during the stationary phase, during which capsular polysaccharide (CPS) is deposited around the cells. In contrast $R$. meliloti, which forms no capsules, produces up to $200 \mathrm{mg} 1,2-\beta$-glucans (g dry cell wt $)^{-1}$. During the stationary phase, this concentration remains constant (Zevenhuizen, 1981; Zevenhuizen \& Van Neerven, 1983).

At high osmotic values of the medium the synthesis of cyclic glucans is repressed in Agrobacterium tumefaciens (Miller et al., 1986). Several authors have reported the formation of compatible solutes in the cytoplasm of cells grown under conditions of high osmotic pressure (Le Rudulier \& Bernard, 1986; Czonka, 1989). At concentrations up to $1.3 \% \mathrm{NaCl}$ growth of $R$. meliloti is not affected, while growth of $R$. leguminosarum biovar trifolii is impaired at $0.4 \% \mathrm{NaCl}$ (Vincent, 1974).

In this paper we report how the osmotic values of the medium affect oligo- and polysaccharide synthesis by Rhizobium meliloti strain SU-47. Comparison is made with other $R$. meliloti and $A$. tumefaciens strains. A role for cellular and capsular carbohydrates in osmoregulation is also discussed. 


\section{Methods}

Organisms and cultivation. The following strains were obtained from the culture collection of the Department of Microbiology, Wageningen, The Netherlands: Rhizobium meliloti strains SU-47, SU-255, and SU256; Agrobacterium tumefaciens strains PD15, PD18 and PD51. These bacteria were maintained on agar slants of Rhizobium medium containing yeast extract, mannitol and mineral salts. Precultures were prepared by inoculating the organism into 'standard medium' containing $5 \mathrm{~g}$ mannitol and $1 \mathrm{~g}$ glutamic acid litre ${ }^{-1}$, and mineral salts and vitamins according to Zevenhuizen (1986). The term 'production medium' is used when the mannitol concentration was $10 \mathrm{~g} \mathrm{l}^{-1}$. In the experiments on osmoregulation media were supplemented with $\mathrm{NaCl}$, other electrolytes or non-electrolytes as indicated.

Cells from the late exponential phase were used as inoculum $(1 \%$, $\mathrm{v} / \mathrm{v}$ ). They were cultivated at $25^{\circ} \mathrm{C}$ in $50 \mathrm{ml}$ medium in 100 or $300 \mathrm{ml}$ Erlenmeyer flasks at $25^{\circ} \mathrm{C}$. To obtain larger quantities of cultures, cells were grown in $300 \mathrm{ml}$ medium in 2 litre Erlenmeyer flasks. The flasks were incubated on a rotary shaker at 200 r.p.m. Experiments with controlled $\mathrm{pH}$ and oxygen supply were done in a 2 litre batch fermenter with 1 litre of medium. The culture was aerated at the rate of 11 air $\mathrm{min}^{-1}$, and stirred at 500 r.p.m.

Calculation of osmotic pressure. The osmotic pressure $\pi$ was calculated as $\pi=\Sigma n_{\mathrm{i}} \cdot \mathrm{M}_{\mathrm{i}} \cdot \mathbf{R} \cdot T$ where $n=$ no. of moles of solute $i, \mathrm{M}=$ molarity of the solute $i\left(\mathrm{~mol} \mathrm{l}^{-1}\right), \mathbf{R}=0.08211 \mathrm{~atm} \mathrm{~K} \mathrm{Kol}^{-1}$, and $T=298.15^{\circ} \mathrm{K}$. Ideal behaviour of the solutions is assumed (Chang, 1977). The osmotic pressure of the production medium was calculated as $2.0 \mathrm{~atm}$ $(1 \mathrm{~atm}=101325 \mathrm{~Pa})$.

Analysis of the cultures. Cells and culture supernatant were separated by centrifugation at $35000 \mathrm{~g}$ for $30 \mathrm{~min}$. Highly viscous cultures were first diluted with distilled water prior to centrifugation. Cell pellets from $50 \mathrm{ml}$ cultures were resuspended in $10 \mathrm{ml}$ distilled water and briefly sonicated to obtain a homogeneous suspension.

Supernatant. The supernatant was analysed for total excreted carbohydrates by the anthrone- $\mathrm{H}_{2} \mathrm{SO}_{4}$ method (Trevelyan \& Harrison, 1952). The carbohydrate concentration was expressed as glucose equivalents. Mannitol was measured by the periodate oxidationchromotropic acid colorimetric method (Burton, 1957). Viscosity measurements were made with an Ubbelohde viscometer at $25^{\circ} \mathrm{C}$.

Excreted carbohydrate was fractionated into a low $-M_{\mathrm{r}}$ and a high- $M_{\mathrm{r}}$ fraction by precipitating the high $-M_{\mathrm{r}}$ fraction with 3 vols ethanol. The precipitated succinoglycan was redissolved in water, and the sugar content was measured by the anthrone- $\mathrm{H}_{2} \mathrm{SO}_{4}$ assay. Repeating units of succinoglycan which remained in the ethanolic supernatant were also quantified by the anthrone- $\mathrm{H}_{2} \mathrm{SO}_{4}$ assay. The extracellular low- $M_{\mathrm{r}}$ carbohydrates of this fraction were separated according to charge on a DEAE-Sepharose anion-exchange column $(3 \times 25 \mathrm{~cm}$, PharmaciaLKB), and were eluted with distilled water followed by a linear $\mathrm{KCl}$ gradient $(0-0.5 \mathrm{M})$. Fractions $(5 \mathrm{ml})$ were collected, and checked for hexose content by the anthrone method. Peak fractions were desalted by gel-filtration over a Bio-Gel P2 column. The amount of succinate found within the collected peak fractions after methanolysis was determined as methylsuccinate on a capillary Wax 57-CB column (Chrompack) connected to a flame ionization detector in a Kipp Analytica 8200 gas chromatograph at $100^{\circ} \mathrm{C}$ (Zevenhuizen \& Van Neerven, 1983).

Cell pellet. Fractionation into high- $M_{\mathrm{r}}$ and low- $M_{\mathrm{r}}$ cellular carbohydrates was as follows. Cell suspensions of $A$. tumefaciens were extracted with 1 vol. $2 \mathrm{M}-\mathrm{NaOH}$ for $15 \mathrm{~min}$ at $70^{\circ} \mathrm{C}$. After centrifugation, the $\mathrm{NaOH}$ extract was decanted. Ethanol (1 vol.) was added to this extract, which precipitated CPS [curdlan, a linear 1,3- $\beta$-glucan (Hisamatsu et al., 1978)]. The precipitate was collected by centrifugation, and redissolved in $1 \mathrm{M}-\mathrm{NaOH}$. Curdlan was quantified by the anthrone method and expressed as glucose equivalents. In the ethanolic extract, containing cyclic 1,2- $\beta$ - glucans and oligosaccharides, total carbohydrate was measured by the anthrone assay. In the case of $R$. meliloti strains, which do not produce CPS, cell suspensions were extracted with 3 vols ethanol for $30 \mathrm{~min}$ at $70^{\circ} \mathrm{C}$, followed by centrifugation and resuspension of the extracted cells in water. The hexose content of this suspension was determined by the anthrone method and could be taken as a measure of the glycogen content of the cells (Zevenhuizen, 1981). In the ethanolic extract, low- $M_{\mathrm{r}}$ carbohydrates (cyclic glucans and oligosaccharides) were present. These were separated after evaporation of the ethanol on a column of Ultrogel AcA-202 $\left(2.5 \times 37 \mathrm{~cm} ; M_{\mathrm{r}}\right.$ range 1000-15000; Pharmacia-LKB) with water as the eluent. Fractions of about $2.5 \mathrm{ml}$ were collected and measured for hexose content.

TLC was done out on silica gel plates (Merck) with the solvent [n-butanol/ethanol/water $(5: 5: 4$, by vol.)] ascending the plates (Amemura et al., 1985). Cell protein was measured according to the Lowry method with BSA as standard. PHB was determined after methanolysis of whole cell suspensions with GLC on a capillary Wax 57-CB column at $100^{\circ} \mathrm{C}$ by the method of Braunegg et al. (1978).

Sugar composition and linkage types of isolated poly- and oligosaccharides. Separation of neutral sugar components was done after hydrolysis and conversion of the liberated sugars into alditol acetates by GLC (Blakeney et al., 1983). Glycosidic linkages were determined after methylation analysis according to Harris et al. (1984). With both GLC experiments a capillary Sil 43-CB column (Chrompack) was used at $210^{\circ} \mathrm{C}$. HPLC of glucans and oligosaccharides was done according to Breedveld et al. (1990). ${ }^{1} \mathrm{H}-\mathrm{NMR}$ was done with a Bruker Ac-200E apparatus with 4,4'-dimethyl-4-silapentane sulphonate (DDS) as internal standard.

\section{Results}

\section{Influence of $\mathrm{NaCl}$ and other osmolytes on extracellular and cellular carbohydrate production by $R$. meliloti and A. tumefaciens}

A difference in succinoglycan production between $\boldsymbol{A}$. tumefaciens and $R$. meliloti strains was observed (Table 1). The $A$. tumefaciens strains PD15, PD18 and PD51 formed highly viscous cultures in production medium without and with added $\mathrm{NaCl}$. With $R$. meliloti strains SU-47, SU-255 and SU-256 the major part (70-80\%) of the extracellular carbohydrate produced in the $\mathrm{NaCl}-$ free medium was of low- $M_{\mathrm{r}}$. By adding $\mathrm{NaCl}$ to the medium the proportion of high- $M_{\mathrm{r}}$ succinoglycan was greatly enhanced. Succinoglycan production was parallelled by an increase in viscosity of the medium (data not shown).

The low content of low- $M_{\mathrm{r}}$ cellular carbohydrates (1,2$\beta$-glucans) and the high curdlan content of $A$. tumefaciens cells in media not supplemented with $\mathrm{NaCl}$ was in contrast to the higher amounts of 1,2- $\beta$-glucans of $R$. meliloti cells, which did not produce capsules. At increasing $\mathrm{NaCl}$ concentrations, large amounts of oligosaccharides were synthesized, functioning probably as compatible osmoregulants in the cytosol of the cells (see below for $R$. meliloti SU-47). 
Table 1. NaCl-induced osmotic effects on extracellular and cellular carbohydrates of $A$. tumefaciens and $R$. meliloti strains

Cultures were incubated in production medium (with $\mathrm{NaCl}$ added as indicated) for $14 \mathrm{~d}$ on a rotary shaker ( 200 r.p.m.) at $25^{\circ} \mathrm{C}$. Carbohydrate contents are expressed as $\mathrm{mg}$ glucose equivalents per litre of eulture. The data shown here are representative of two experiments between which values varied not more than $5 \%$.

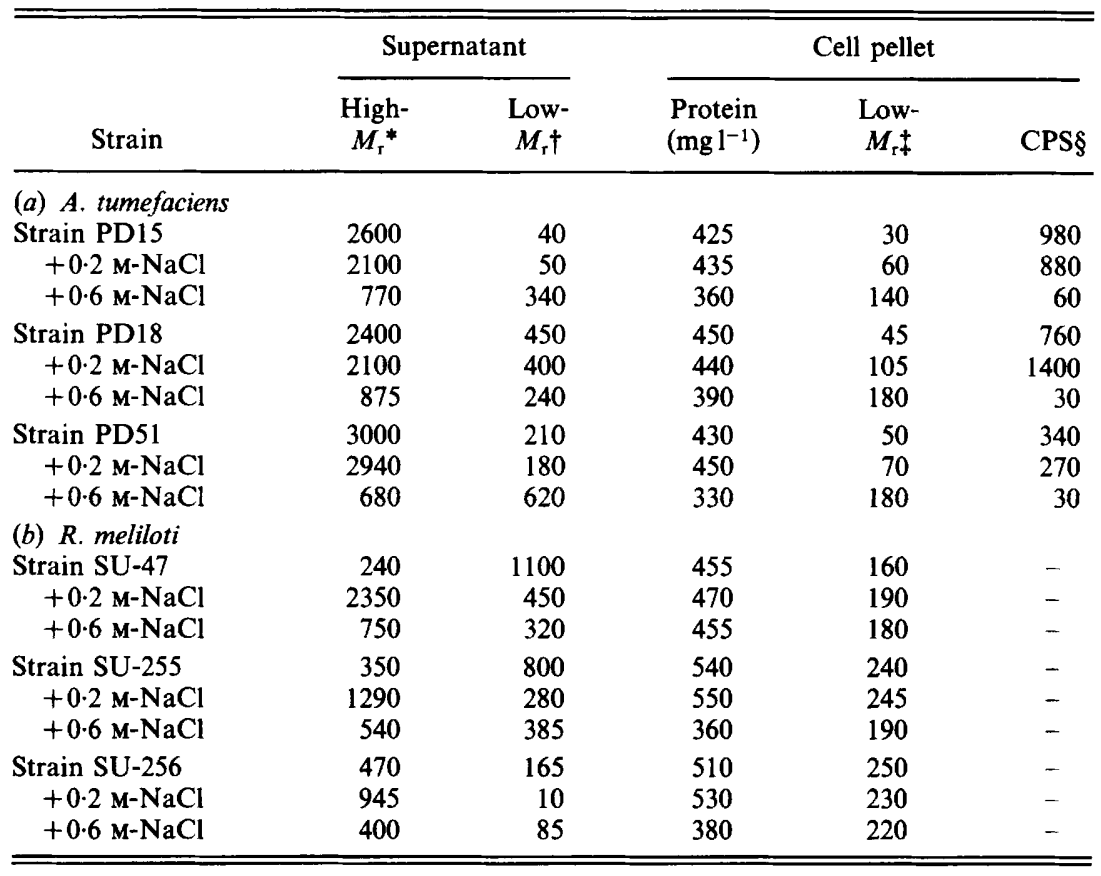

* High- $M_{\mathrm{r}}$ carbohydrates in supernatant (succinoglycan) quantified as $\mathrm{mg}$ glucose equivalents per litre of culture.

$\dagger$ Low $-M_{\mathrm{r}}$ carbohydrates in supernatant quantified as mg glucose equivalents per litre of culture.

$\ddagger$ Low $-M_{\mathrm{r}}$ carbohydrates in pellet (cyclic glucans + oligosaccharides) quantified as $\mathrm{mg}$ glucose equivalents per litre of culture.

$\S$ Curdlan quantified as $\mathrm{mg}$ glucose equivalents per litre of culture; absent in $R$. meliloti.

The production of succinoglycan in media supplemented with $0.6 \mathrm{M}$ - as compared to $0.2 \mathrm{M}-\mathrm{NaCl}$ was lowered in all strains tested. Curdlan production in Agrobacterium was strongly reduced in these media. None of the strains were able to grow in the presence of $1 \mathrm{M}-\mathrm{NaCl}$.

To distinguish between an ion-specific $\left(\mathrm{Na}^{+}, \mathrm{Cl}^{-}\right)$and a general osmotic effect on succinoglycan production by $R$. meliloti SU-47 various ions and non-ionic osmolytes were tested (Table 2). Initial experiments showed that $0 \cdot 2 \mathrm{M}-\mathrm{NaCl}$ was the optimal $\mathrm{NaCl}$ concentration for succinoglycan production by strain SU-47. With divalent ions $\left(\mathrm{CaCl}_{2}, \mathrm{MgCl}_{2}, \mathrm{MgSO}_{4}\right.$ and $\left.\mathrm{Na}_{2} \mathrm{SO}_{4}\right)$ much lower concentrations $(25 \mathrm{mM})$ were needed for an even higher production on succinoglycan and a higher viscosity of the cultures. Stimulation of succinoglycan production and concomitant rise in viscosity occurred also with $0.2 \mathrm{M}$ $\mathrm{KCl}$ and high concentrations of mannitol. Sucrose
$(0.5 \mathrm{M})$ also stimulated succinoglycan production as could be seen from a rise in viscosity (because sucrose interfered with the anthrone assay, results were not shown).

\section{Osmotic effects on excretion of extracellular} carbohydrates of $R$. meliloti $S U-47$ at different incubation times

R. meliloti SU-47 was cultivated in the presence or absence of $0.2 \mathrm{M}-\mathrm{NaCl}$ in a well-aerated batch-fermenter (Fig. 1). Hardly any differences in growth rate and substrate uptake were observed. In both cases, synthesis of extracellular carbohydrates occurred mainly in the stationary phase. Because of the high carbon/nitrogen ratio of the medium not all the mannitol was consumed. The total amount of carbohydrate material excreted was higher in the $\mathrm{NaCl}$-supplemented medium, and, as a 


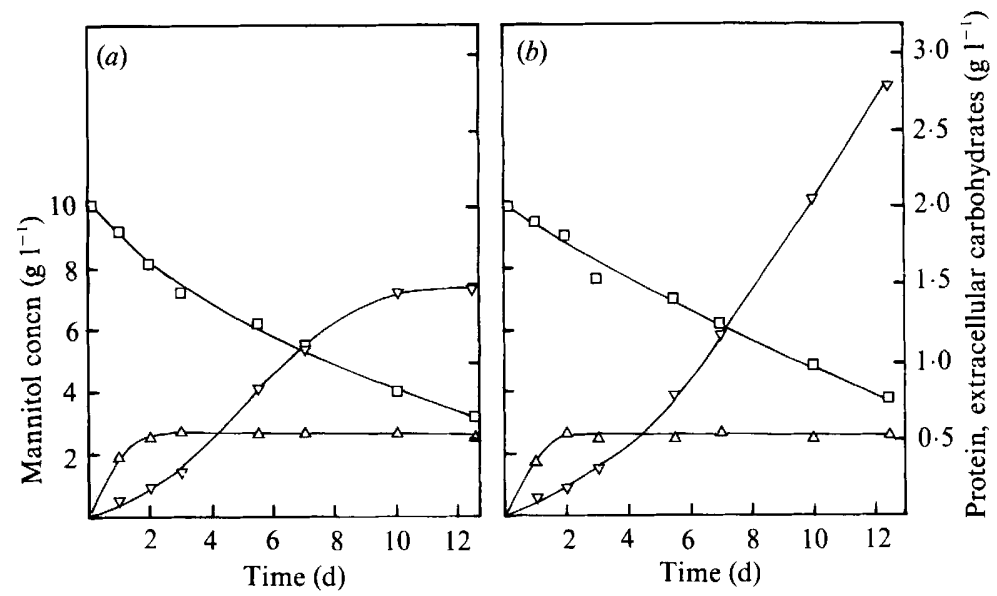

Fig. 1. Growth (as protein; $\triangle$ ), production of exocellular carbohydrates $(\nabla)$ and mannitol consumption $(\square)$ by $R$. meliloti SU-47 at $25^{\circ} \mathrm{C}$ as a function of time in production medium without $(a)$ and with $(b) 0.2 \mathrm{M}-\mathrm{NaCl}$.

Table 2. Osmotically induced cellular and extracellular carbohydrate synthesis by $R$. meliloti $S U-47$

Cultures were incubated for $14 \mathrm{~d}$ at $25^{\circ} \mathrm{C}$ on a rotary shaker (200 r.p.m.) in production medium (with additions as indicated). The data shown here are representative of two experiments between which values varied not more than $10 \%$.

\begin{tabular}{|c|c|c|c|c|c|c|}
\hline \multirow[b]{2}{*}{ Addition } & \multirow{2}{*}{$\begin{array}{c}\text { Osmotic } \\
\text { pressure } \\
(\mathrm{atm})^{*}\end{array}$} & \multicolumn{3}{|c|}{ Supernatant } & \multicolumn{2}{|c|}{ Cell pellet } \\
\hline & & $\begin{array}{l}\text { Viscosity } \\
\text { (cP) }\end{array}$ & $\begin{array}{c}\text { High- } \\
M_{\mathrm{r}} \dagger\end{array}$ & $\begin{array}{c}\text { Low- } \\
M_{\mathrm{r}} \ddagger\end{array}$ & $\begin{array}{c}\text { Low- } \\
M_{\mathrm{r}} \S\end{array}$ & $\begin{array}{l}\text { Protein } \\
\left(\mathrm{mg} \mathrm{1}^{-1}\right)\end{array}$ \\
\hline None & $2 \cdot 0$ & 1.5 & 240 & 1100 & 160 & 455 \\
\hline $200 \mathrm{mM}-\mathrm{NaCl}$ & $11 \cdot 8$ & 30 & 2330 & 470 & 190 & 470 \\
\hline $200 \mathrm{mM}-\mathrm{KCl}$ & 11.8 & 45 & 2280 & 290 & 140 & 445 \\
\hline $25 \mathrm{mM}-\mathrm{Na}_{2} \mathrm{SO}_{4}$ & 3.8 & 75 & 2870 & 660 & 155 & 420 \\
\hline $25 \mathrm{mM}-\mathrm{MgCl}_{2}$ & 3.8 & 92 & 2990 & 120 & 210 & 450 \\
\hline $25 \mathrm{mM}-\mathrm{CaCl}_{2}$ & 3.8 & ND & 2400 & 130 & 205 & 455 \\
\hline $500 \mathrm{mM}$-mannitol & $14 \cdot 2$ & 80 & 2700 & 700 & 180 & 395 \\
\hline
\end{tabular}

ND, Not determined; the culture had to be diluted prior to centrifugation because of high viscosity.

* $\pi=\Sigma n_{\mathrm{i}} \cdot M_{\mathrm{i}} \cdot \mathbf{R} \cdot T$ with $\pi=$ calculated osmotic pressure, $n=$ no. of moles of solute, $\mathrm{M}=$ molarity of the solutes, $\mathbf{R}=$ gas constant and $T=$ absolute temperature (see Methods). (1 atm $=101325 \mathrm{~Pa}$.)

$\dagger$ High $M_{\mathrm{r}}$ succinoglycan quantified as $\mathrm{mg}$ glucose equivalents per litre of culture.

$\ddagger$ Low $M_{\mathrm{r}}$ extracellular carbohydrates quantified as mg glucose equivalents per litre of culture.

$\S$ Low $M_{\mathrm{r}}$ cellular carbohydrates quantified as mg glucose equivalents per litre of culture.

consequence, the viscosity $(28 \mathrm{cP}$ at $0.2 \mathrm{M}-\mathrm{NaCl}$ vs $1.5 \mathrm{cP}$ without added $\mathrm{NaCl}$ ) also. Although in Erlenmeyer flasks oxygen limitation might have occurred, the distribution of both high- and low- $M_{\mathrm{r}}$ carbohydrates was very much comparable to that shown in Table 1 . As the $\mathrm{pH}$ in $\mathrm{NaCl}$-supplemented media often fell below 5.5 during incubation an experiment was set up in a batch fermenter with the $\mathrm{pH}$ set at 7.0. No differences from the data in Fig. 1 were observed.

Succinoglycan production was also enhanced by solely elevating the concentrations of medium components. In a medium with $40 \mathrm{~g}$ mannitol, $8 \mathrm{~g}$ glutamic acid and 8 times the concentration of salts and vitamins $(8 \times$ GMS medium), $7.8 \mathrm{~g}$ succinoglycan per litre of medium $(95 \%$ of the total extracellular carbohydrate fraction) was produced by a biomass of $4 \mathrm{~g}$ protein (Fig. 2).

\section{Identification of extracellular carbohydrates}

Both the high- and low- $M_{\mathrm{r}}$ carbohydrate fractions showed glucose :galactose ratios of $6 \cdot 5-7 \cdot 2: 1$ as determined by component analysis. This agrees with succino- 


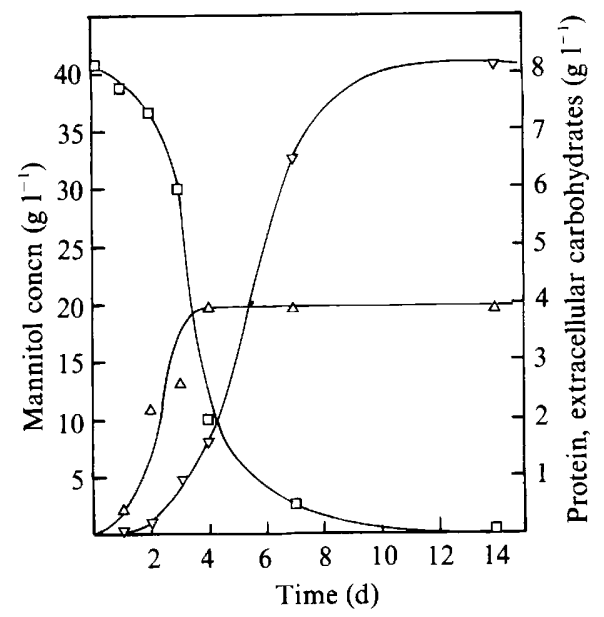

Fig. 2. Growth, succinoglycan production and mannitol consumption by $R$. meliloti SU-47 at $25^{\circ} \mathrm{C}$ as a function of time in a medium containing $\left(1^{-1}\right) 40 \mathrm{~g}$ mannitol and $8 \mathrm{~g}$ glutamic acid. Symbols, as Fig. 1.

glycan having a glucose:galactose ratio of $7: 1$. To exclude interference from excreted cyclic glucans, the low- $M_{\mathrm{r}}$ carbohydrate fraction of $R$. meliloti SU-47 cultures grown in the presence or absence of $0.2 \mathrm{M}-\mathrm{NaCl}$ was chromatographed with a DEAE-Sepharose anionexchange column. In the experiment without added $\mathrm{NaCl}$, three peaks were obtained. They corresponded to the repeat-units of succinoglycan having 0 (peak I, $5 \%$ ), 1 (II, $35 \%$ ) and 2 (III, $60 \%$ ) succinate substituents per repeat-unit, respectively. With $0 \cdot 2 \mathrm{M}-\mathrm{NaCl}$, peak I could not be detected while peak II was predominant $(70 \%)$. In neither case were cyclic glucans detected.
Influence of $\mathrm{NaCl}$ on cellular carbohydrates of $\mathrm{R}$. meliloti strain $S U-47$

R. meliloti SU-47 was grown in standard medium containing 0 or $0.6 \mathrm{M}-\mathrm{NaCl}$ at $25^{\circ} \mathrm{C}$, and analysed at different time intervals (Table 3 ). When inoculating cells from salt-free medium into standard medium containing $0.6 \mathrm{M}-\mathrm{NaCl}$, maximal cell yield was obtained after $4 \mathrm{~d}$ instead of $2 \mathrm{~d}$. Most striking was the absence of glycogen at $0.6 \mathrm{M}-\mathrm{NaCl}$. Without added $\mathrm{NaCl}$, glycogen accumulation occurred within $2 \mathrm{~d}$. Thereafter the glycogen disappeared gradually. PHB synthesis was unaffected by $\mathrm{NaCl}$. At both 0 and $0.6 \mathrm{M}-\mathrm{NaCl}$, a large fraction of cellular low- $M_{\mathrm{r}}$ carbohydrates was present, which remained constant during the whole incubation period (see below).

\section{Identification of low-Mr cellular carbohydrates}

The low- $M_{\mathrm{r}}$ carbohydrate fractions from cells of $R$. meliloti SU-47 grown at 0 and $0.6 \mathrm{M}-\mathrm{NaCl}$ were separated on a gel-filtration column (Fig. $3 a, b$ ). With cells grown in the absence of added $\mathrm{NaCl}$ almost all carbohydrates detected were glucans (Fig. 3), both charged (peak I) and uncharged (peak II). With $\mathrm{NaCl}$-grown cells, a low- $M_{\mathrm{r}}$ oligosaccharide fraction became predominant (peak III), whereas the total amount of glucans was lowered, especially the charged glucans (Table 4).

Peak fractions were collected and freeze-dried. Component analysis of all peaks revealed exclusively glucose as the sugar constituent. Peak fractions I, II and III were further separated by TLC on silica gel. Peak II displayed

Table 3. Growth (as cell protein), cellular carbohydrates and PHB formation in $R$. meliloti $S U-47$ grown in the presence or absence of $0.6 \mathrm{M}-\mathrm{NaCl}$ during the course of incubation

Cells were incubated at $25^{\circ} \mathrm{C}$ on a rotary shaker (200 r.p.m.) in standard medium. The data shown here are representative of at least three experiments.

\begin{tabular}{lccccc}
\hline \hline & $\begin{array}{c}\text { Time } \\
(\mathrm{d})\end{array}$ & $\begin{array}{c}\text { High- } \\
M_{\mathrm{r}}^{*}\end{array}$ & $\begin{array}{c}\text { Low- } \\
M_{\mathrm{r}}^{\dagger}\end{array}$ & $\begin{array}{c}\text { Protein } \\
\left(\mathrm{mg} \mathrm{1}^{-1}\right)\end{array}$ & $\begin{array}{c}\text { PHB } \\
\left(\mathrm{mg} \mathrm{1}^{-1}\right)\end{array}$ \\
\hline No NaCl & 2 & 340 & 125 & 510 & 75 \\
& 4 & 280 & 150 & 500 & 225 \\
& 7 & 250 & 170 & 475 & 250 \\
$0.6 \mathrm{M}-\mathrm{NaCl}$ & 10 & 170 & 170 & 480 & 180 \\
& 2 & 10 & 0 & 240 & 0 \\
& 4 & 30 & 210 & 475 & 185 \\
& 7 & 35 & 215 & 425 & 215 \\
& 10 & 35 & 225 & 425 & 180 \\
\hline \hline
\end{tabular}

* High- $M_{\mathrm{r}}$ cellular carbohydrates (glycogen) in mg glucose equivalents per litre of culture.

† Low- $M_{\mathrm{r}}$ cellular carbohydrates (cyclic glucans and oligosaccharides) in $\mathrm{mg}$ glucose equivalents per litre of culture. 

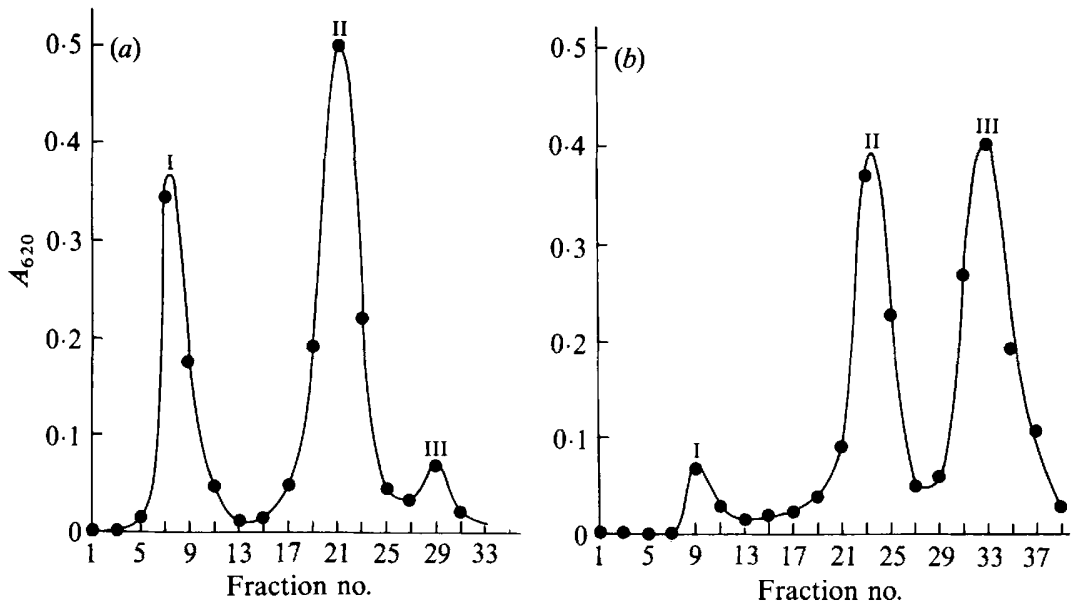

Fig. 3. Gel chromatography on Ultrogel AcA-202 of low- $M_{\mathrm{r}}$ cellular carbohydrates of $R$. meliloti SU-47. Cells were cultivated at $25^{\circ} \mathrm{C}$ in standard medium without $(a)$ and with $(b) 0.6 \mathrm{M}-\mathrm{NaCl}$.

Table 4. Distribution of the cellular low-M $M_{r}$ fractions (cyclic glucans and oligosaccharides) of $R$. meliloti $S U-47$ grown at different $\mathrm{NaCl}$ concentrations

Peak fractions I, II and III were obtained after gel-permeation chromatography (Fig. 3). Values are expressed relative to the total low- $M_{\mathrm{r}}$ fraction $(100 \%)$.

\begin{tabular}{|c|c|c|c|c|}
\hline \multirow{2}{*}{$\begin{array}{l}\mathrm{NaCl} \\
\text { concn } \\
\text { (M) }\end{array}$} & \multicolumn{3}{|c|}{$\begin{array}{l}\text { Percentage of total low- } M_{\mathrm{r}} \\
\text { cellular fraction: }\end{array}$} & \multirow[b]{2}{*}{ Total $^{*}$} \\
\hline & I & II & III & \\
\hline 0 & 35 & 61 & 4 & 160 \\
\hline 0.2 & 24 & 45 & 31 & 190 \\
\hline 0.4 & 10 & 39 & 51 & 155 \\
\hline 0.6 & 6 & 34 & 60 & 160 \\
\hline
\end{tabular}

* Total cellular low- $M_{\mathrm{r}}$ carbohydrates in mg glucose equivalents per litre of culture.

a pattern of bands of neutral cyclic $1,2-\beta$-glucans of DPs 19-25 (Zevenhuizen et al., 1990). Peak I gave a pattern of closely situated bands that moved at faster rates. These bands have been identified as glycerol-1-phosphatesubstituted cyclic glucans (Batley et al., 1987; Zevenhuizen et al., 1990). On methylation analysis of peak I and II the principal linkage was found to be 1,2- since only 3,4,6-tri- $O$-methyl-D-glucose was detected. With HPLC, ring cycles with DPs of 17-29 could be found.

Peak III consisted of gluco-oligosaccharides with DPs of 2-6. The DP values were determined by comparing the $R_{F}$ values of the gluco-oligosaccharides with those of a series of sophoro-oligosaccharides. These were obtained by partial hydrolysis of $1,2-\beta$-glucans and analysed by HPLC and TLC (results not shown). Methylation analysis of peak III fractions from cells cultivated at various salt concentrations yielded 2,3,4,6-

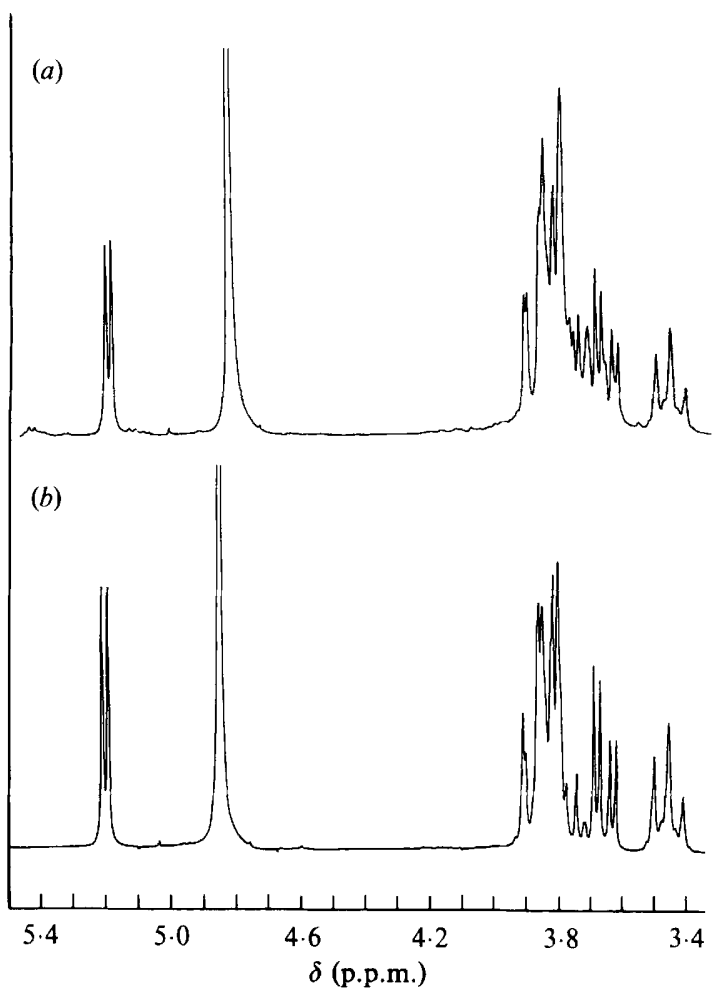

Fig. 4. ${ }^{1} \mathrm{H}-\mathrm{NMR}$ spectra of peak fraction III (a) taken from the experiment in Table $4(0.4 \mathrm{M}-\mathrm{NaCl})$ compared with that of $\alpha, \alpha$ trehalose (b). Concentration $20 \mathrm{mg} \mathrm{D}_{2} \mathrm{O} \mathrm{ml} \mathrm{m}^{-1}$.

tetra- $O$-methyl-D-glucose and 3,4,6-tri- $O$-methyl-D-glucose in the ratios $95: 5$ at $0.6 \mathrm{M}-\mathrm{NaCl}, 84: 16$ at $0.4 \mathrm{M}-$ $\mathrm{NaCl}$, and $62: 38$ at $0.2 \mathrm{M}-\mathrm{NaCl}$. These data show that the 1,1- bond was predominant in all cases tested, indicating a trehalose structure. Some 1,2- bonds were also present in the higher oligosaccharides, with a maximum at $0.2 \mathrm{M}-\mathrm{NaCl}$. Peak III fractions were subjected to ${ }^{1} \mathrm{H}-\mathrm{NMR}$ with trehalose as a reference. The 
spectra for the oligosaccharide fraction of peak III from cells grown at $0.4 \mathrm{M}-\mathrm{NaCl}$ and pure trehalose ( $\alpha-\mathrm{D}$ glucopyranosyl $\alpha$-D-glucopyranoside) were identical (Fig. 4). Most characteristic is the resonance at $5 \cdot 20$ p.p.m. $\left(J_{1}-J_{2}=3.3 \mathrm{~Hz}\right)$ as a result of the $\alpha$-anomeric protons (Usui et al., 1974). As in $\alpha, \alpha$-trehalose the two glucose residues are identical, only one doublet being observed. Some very weak signals in the region between $5 \cdot 0-5 \cdot 5$ could be observed as well, possibly due to anomeric protons of glucose in the 1,2- $\alpha$-configuration.

\section{Discussion}

Osmoregulation at low osmolarity

Cyclic glucans of Agrobacterium and Rhizobium are localized in the periplasmic space, have an intermediate $M_{\mathrm{r}}$ of about 3500 , and contain a 1,2- $\beta$-glucan backbone. Because of their structural resemblance to the so-called membrane-derived oligosaccharides (MDO) of E. coli (Schulman \& Kennedy, 1979), the regulation of the biosynthesis of cyclic glucans is comparable (Miller et al., 1986). At low osmotic values of the medium a net flow of water into the cytosol takes place leading to an increase of turgor pressure, and therefore it was supposed that the periplasm tends to remain iso-osmotic with the cytoplasm (Stock et al., 1977). The neutral and especially the anionic periplasmic cyclic glucans may be very well suited as a fixed osmolyte for increasing the turgor pressure in the periplasm against the cytoplasmic membrane (Miller et al., 1986, 1987).

$R$. leguminosarum cells (all biovars) build up considerable amounts of $1,2-\beta$-glucans during the exponential growth phase, but during the stationary phase their glucan content falls. At this point the cells became embedded in a CPS-matrix (Zevenhuizen, 1981, 1984). It appears that strains of $R$. leguminosarum grown in standard medium combine a low 1,-2- $\beta$-glucan concentration with a high deposition of CPS as is the case with $A$. tumefaciens cells. However $R$. meliloti cells, which do not form capsules, usually have constantly high $1,2-\beta$ glucan concentrations (Table 1). Therefore, we suggest that both properties - constant high periplasmic $1,2-\beta$ glucan concentration and the presence of capsular material - can be mechanisms for cells of the Rhizobiaceae to maintain their integrity in standard medium of low osmolarity.

Capsular polysaccharides could very well function to counteract the turgor pressure of the cells against the outer membrane. Studies on isolated curdlan of $A$. tumefaciens and of CPS of $R$. leguminosarum biovar trifolii TA-1 have shown that these polymers form strong gels in water (gel strength about $500 \mathrm{~g} \mathrm{~cm}^{-2}$ of a $1 \%$ CPS solution; Zevenhuizen, 1984). These gelling matrices may act mechanically against the turgor pressure of the cells in vivo also.

At certain critical conditions of osmolarity and of temperature, when cells of $R$. leguminosarum biovars viciae and trifolii are unable to form CPS and can form small amounts of EPS only, continuous 1,2- $\beta$-glucan excretion into the medium takes place in amounts up to several grams per litre (Breedveld et al., 1990). It thus seems that in biovars of $R$. leguminosarum, which are osmotically and temperature sensitive, $1,2-\beta$-glucan synthesis is the first action undertaken by the cells in an effort to maintain cell integrity. $R$. meliloti cells, which are osmotically much more tolerant, are not deregulated in such a way, but can maintain a high glucan concentration within their cells at low osmolarity.

The ring size distribution of the cyclic glucans from $R$. meliloti SU-47, as determined by HPLC, is clearly different from that of $R$. leguminosarum biovar trifolii TA-1 (Breedveld et al., 1990), namely DPs 17-29 and $17-25$, respectively. The proportion of the glucans which were glycerol-phosphorylated was $40 \%$ in $R$. meliloti SU-47 while substituted glucans were not detected, or formed a minor fraction, in $R$. leguminosarum biovars (Zevenhuizen et al., 1990).

\section{Osmoregulation at high osmolarity}

When $A$. tumefaciens C58 was grown in yeast extractmannitol medium supplemented with $0.4 \mathrm{M}-\mathrm{NaCl}$, the amount of both the neutral and the anionic cyclic glucan fraction was strikingly lower in comparison to the situation without added $\mathrm{NaCl}$ (Miller et al., 1986). No osmoregulatory function can be ascribed for periplasmic $1,2-\beta$-glucans in media with high $\mathrm{NaCl}$ concentrations. However, the neutral cyclic glucans were still synthesized by $R$. meliloti SU-47, although at a lower level.

In media containing $\mathrm{NaCl}$, a considerable increase of oligosaccharides was observed, with DP $=2$ [trehalose,

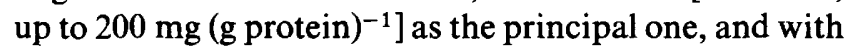
minor amounts of oligomers of DPs' 4-6. Their accumulation at high osmotic values of the medium is most likely to function as osmoregulants for the cytoplasm of the cell. Because of the presence of 1,2- and 1,1- linkages in these latter oligosaccharides they are probably identical with the three koji-oligosaccharides (containing 1,2- $\alpha-$ bonds and a terminal 1,1- $\alpha$-bond) of DPs 4-6 from cultures of $R$. meliloti $\mathrm{J} 7017$ studied by Hisamatsu et al. (1985). These authors detected the non-reducing oligosaccharides after ethanol extraction of whole cell cultures without reporting the origin (cellular or extracellular) of the molecules.

Trehalose was found in small quantities, varying from $1-20 \mathrm{mg}(\mathrm{g} \text { dry wt})^{-1}$ within the cytoplasm of cells of Rhizobium spp. grown in media of low osmolarity (Streeter, 1985). The high cellular low- $M_{\mathrm{r}}$ carbohydrate 
content detected in A. tumefaciens cells grown at $0.4 \mathrm{M}$ $\mathrm{NaCl}$ by Miller et al. (1986) was probably due to trehalose as osmoprotectant. Recently, Dylan et al. (1990) showed that $R$. meliloti 102F34 mutants defective in $1,2-\beta$-glucan accumulation were impaired in their growth rate under low-osmotic conditions as compared to the wild-type. Their growth was restored by raising the osmolarity of the medium, at which point a cellular low$M_{\mathrm{r}}$ oligosaccharide appeared, apparently trehalose. As is shown in these examples, the cellular low- $M_{\mathrm{r}}$ carbohydrate fraction did not consist solely of cyclic glucans. We found evidence that the majority of the cellular low- $M_{\mathrm{r}}$ carbohydrate fraction in $\mathrm{NaCl}$-supplemented media consisted of trehalose.

It is important to keep in mind that the nature of the medium and the growth phase can influence the amount of trehalose synthesized. In carbon-rich media as used in our study high concentrations of various carbohydrates can be obtained. In nitrogen-rich media and at other growth phases different osmoregulatory mechanisms may take place, like glycine, proline and betaine accumulation (Le Rudulier \& Bernard, 1986; Czonka, 1989).

\section{EPS and osmoregulation}

Osmotically induced changes in extracellular polysaccharide production have been reported for a Pseudomonas aeruginosa strain (Berry et al., 1989). With $A$. tumefaciens strains, and with $A$. radiobacter NCIB 11883 (Linton et al., 1987), succinoglycan was produced in media of low osmotic strength. The production of 2-4 g succinoglycan (g protein) ${ }^{-1}$ by $R$. meliloti $\mathrm{SU}-47$ was comparable to the data reported for $R$. meliloti $\mathrm{J} 7017$ and $R$. leguminosarum biovar trifolii $\mathrm{J} 60$ by Amemura et al. (1983). Although these authors found acidic oligosaccharides and succinoglycan in addition to cyclic glucans in the medium, we did not find extracellular cyclic glucans for strain SU-47.

Many reports claim strong correlations between functional genes needed for succinoglycan biosynthesis and the ability of $R$. meliloti to invade root hairs (Leigh $e t$ al., 1985; Zhan et al., 1989) or to induce the formation of nodules (Long et al., 1988). The differences in the relative production of high- and low- $M_{\mathrm{r}}$ extracellular carbohydrates depending on the environmental osmolarity, as was found for different $R$. meliloti strains, may be related to this phenomenon.

It has been shown that growth of $R$. meliloti NSI was inhibited by various salts depending on the specific ion rather than the increase in osmolarity (Botsford, 1984). Our report shows that succinoglycan production by $R$. meliloti appeared to be enhanced by increasing osmotic pressure. With increasing succinoglycan production viscosity rose, but the relatively small differences in production of EPS by $R$. meliloti SU-47 could not explain the large differences in viscosity, especially with the divalent ions tested. This last phenomenon is probably an effect of a different conformation of the polysaccharide in the presence of divalent ions. This was found for the Ca-form of succinoglycan from Alcaligenes faecalis var. myxogenes 10C3 (Harada \& Amemura, 1981 ) and for the acidic EPSs from $R$. leguminosarum (Morris et al., 1989).

The authors are grateful to Dr. C. Dijkema, Department of Molecular Physics, Agricultural University, Wageningen, who performed the ${ }^{1} \mathrm{H}-\mathrm{NMR}$ experiments, and to Mr. Nees Slotboom for the art-work. This investigation was carried out with the support of the Dutch National Innovation Oriented Program Carbohydrates (IOP-k).

\section{References}

Abe, M., Amemura, A. \& Higashi, A. (1982). Studies on cyclic $\beta$-(1,2)glucan obtained from the periplasmic space of Rhizobium trifolii cells. Plant and Soil 64, 315-324.

Amemura, A., Hisamatsu, M. \& Mitani, H. (1983). Cyclic (1,2)- $\beta$-Dglucan and the octasaccharide repeating units of extracellular acidic polysaccharides produced by Rhizobium. Carbohydrate Research 114, 277-285.

Amemura, A., Footrakul, P., Kolzumi, K., Utamura, T. \& TAGUCHI, $H$. (1985). Isolation of $(1,2)-\beta$-D-glucans from tropical strains of Rhizobium and determination of their degrees of polymerization. Journal of Fermentation Technology 63, 115-120.

Batley, M., Redmond, J. W., Djordjevic, S. P. \& RolfF, B. G. (1987). Characterization of glycerophosphorylated cyclic $\beta-(1,2)-$ glucans from a fast growing Rhizobium species. Biochimica et Biophysica Acta 901, 119-126.

Berry, A., Devault, J. D. \& Chakrabarty, A. M. (1989). High osmolarity is a signal for enhanced alg $D$ transcription in mucoid and nonmucoid Pseudomonas aeruginosa strains. Journal of Bacteriology 171, 2312-2317.

Blakeney, A. B., Harris, P. J., Henry, R. J. \& Stone, B. A. (1983). A simple and rapid preparation of alditol-acetates for monosaccharide analysis. Carbohydrate Research 113, 291-299.

BOTSPORD, J. L. (1984). Osmoregulation in Rhizobium meliloti: inhibition of growth by salts. Archives of Microbiology 137, 124-127.

BraunegG, G., SONNLeiter, B. \& LAFFerTy, R. M. (1978). A rapid gaschromatographic method for the determination of poly- $\beta$ hydroxybutyric acid in microbial biomass. European Journal of Applied Microbiology 6, 29-37.

BReEdVeld, M. W., ZeVenhuizen, L. P. T. M. \& ZehNDeR, A. J. B. (1990). Excessive excretion of cyclic $\beta-(1,2)$-glucan by Rhizobium trifolii TA-1. Applied and Environmental Microbiology 56, 2080-2086.

BURTON, R. M. (1957). The determination of glycerol and dihydroxyacetone. Methods in Enzymology 3, 246-249.

Chang, R. (1977). Physical Chemistry with Applications to Biological Systems. New York: McMillan.

Czonka, L. N. (1989). Physiological and genetic responses of bacteria to osmotic stress. Microbiological Reviews 53, 121-147.

DYlan, T., Helinski, D. R. \& Ditta, G. S. (1990). Hypoosmotic adaptation in Rhizobium meliloti requires $\beta-(1,2)$-glucan. Journal of Bacteriology 172, 1409-1417.

HARADA, T. \& AMEMURA, A. (1981). Bacterial $\beta$-glycans: succinoglycan and curdlan. Memorials of the Institute of Scientific and Industrial Research, Osaka University 38, 37-49.

Harris, P. J., Henry, R. J., Blakeney, A. B. \& Stone, B. A. (1984). An improved procedure for the methylation analysis of oligosaccharides and polysaccharides. Carbohydrate Research 127, 59-73.

Hisamatsu, M., Sano, K., Amemura, A. \& Harada, T. (1978). Acidic polysaccharides containing succinic acid in various strains of Agrobacterium. Carbohydrate Research 61, 89-96. 
Hisamatsu, M., Yamada, T., AKaki, M., Nashinoki, H., TakaI, Y.\& AMEMURA, A. (1985). Structural studies on new, non-reducing oligosaccharides produced by Rhizobium meliloti J7017. Agricultural and Biological Chemistry 49, 1447-1451.

Leigh, J. A., Signer, E. R. \& WalKeR, G. C. (1985). Exopolysaccharide-deficient mutants of Rhizobium meliloti that form ineffective nodules. Proceedings of the National Academy of Sciences of the United States of America 82, 6231-6235.

Le Rudulier, D. \& BERNARD, T. (1986). Salt tolerance in rhizobia: a possible role for betaines. FEMS Microbiology Reviews 39, 6772

Linton, J. D., Evans, M., Jones, D. S. \& Gouldney, D. N. (1987). Exocellular succinoglucan production by $A$ grobacterium radiobacter NCIB 11883. Journal of General Microbiology 133, 2961-2969.

LoNG, S., ReEd, J. W., Himawan, J. \& Walker, G. C. (1988). Genetic analysis of a cluster of genes required for synthesis of the calcofluorbinding exopolysaccharide of Rhizobium meliloti. Journal of Bacteriology 170, 4239-4248.

McIntire, F. C., Peterson, W. H. \& Riker, A. J. (1942). A polysaccharide produced by the crown-gall organism. Journal of Biological Chemistry 143, 491-496.

Miller, K. J., KenNedy, E. P. \& Reinhold, V. N. (1986). Osmotic adaptation by Gram-negative bacteria: possible role for periplasmic oligosaccharides. Science 231, 48-51.

Miller, K. J., Reinhold, V. N., Weissborn, A. C. \& KenNedy, E. P. (1987). Cyclic glucans produced by Agrobacterium tumefaciens are substituted with sn-1-phosphoglycerol residues. Biochimica et Biophysica Acta 901, 112-118.

Morris, V. J., Brownsey, G. J., Harris, J. E., GunNing, A. P., Stevens, B. J. H. \& Johnston, A. W. B. (1989). Cation-dependent gelation of the acidic extracellular polysaccharides of Rhizobium leguminosarum: a non-specific mechanism for the attachment of bacteria to plant roots. Carbohydrate Research 191, 315-320.

Schulman, H. \& KenNedy, E. P. (1979). Localization of membranederived oligosaccharides in the outer envelope of Escherichia coli and their occurrence in other Gram-negative bacteria. Journal of Bacteriology 137, 686-688.
Stock, J. B., Rauch, B. \& Roseman, S. (1977). Periplasmic space in Salmonella typhimurium and Escherichia coli. Journal of Biological Chemistry 252, 7850-7861.

STREETER, J. G. (1985). Accumulation of $\alpha-\alpha$-trehalose by Rhizobium bacteria and bacteroids. Journal of Bacteriology 164, 78-84.

Trevelyan, W. E. \& Harrison, J. S. (1952). Studies on yeast metabolism. I. Fractionation and microdetermination of cell carbohydrates. Biochemical Journal 50, 298-310.

Usui, T., Yokoyama, M., Yamaoka, N., Matsuda, K. \& Tuzimura, K. (1974). Proton magnetic resonance spectra of D-gluco-oligosaccharides and D-glucans. Carbohydrate Research 33, 105-116.

VINCENT, J. M. (1974). Root-nodule symbiosis with Rhizobium. In The Biology of Nitrogen Fixation, pp. 265-342. Edited by A. Quispel. Amsterdam: North Holland Publishing Co.

Zevenhuizen, L. P. T. M. \& Scholten-Koerselman, H. J. (1979). Surface carbohydrates of Rhizobium. I. $\beta-(1,2)$-Glucans. Antonie van Leeuwenhoek 45, 165-175.

Zevenhuizen, L. P. T. M. (1981). Cellular glycogen, $\beta$-(1,2)-glucan, poly- $\beta$-hydroxybutyric acid and extracellular polysaccharides in fast growing species of Rhizobium. Antonie van Leeuwenhoek 47, 481-497.

ZEVenhuizen, L. P. T. M. (1984). Gel-forming capsular polysaccharide of fast-growing rhizobia: occurrence and rheological properties. Applied Microbiology and Biotechnology 20, 393-399.

ZEVENHUIZEN, L. P. T. M. (1986). Selective synthesis of polysaccharides by Rhizobium trifolii strain TA-1. FEMS Microbiology Letters 35, 43-47.

Zevenhuizen, L. P. T. M. \& VAN Neerven, A. R. W. (1983). (1,2)- $\beta$-DGlucan and acidic oligosaccharides produced by Rhizobium meliloti. Carbohydrate Research 118, 127-134.

Zevenhuizen, L. P. T. M., Van Veldhuizen, A. \& Fokkens, R. H. (1990). Re-examination of cellular $\beta$ - $(1,2)$-glucans of Rhizobiaceae: distribution of ring sizes and degrees of glycerol-1-phosphate substitution. Antonie van Leeuwenhoek 57, 173-178.

ZhaN, H., LeVery, S. B., LeE, C. C. \& Leigh, J. A. (1989). A second exopolysaccharide of Rhizobium meliloti strain SU-47 that can function in root nodule invasion. Proceedings of the National Academy of Sciences of the United States of America 86, 3055-3059. 